\title{
СОЦИАЛЬНО-ДЕМОГРАФИЧЕСКИЕ РЕАЛИИ ПАНДЕМИИ
}

\author{
Русанова Н.E.
}

Все зафиксированные в истории пандемии приводили к заметным социально-экономическим изменениям и модернизаџии существующих систем общественного здравоохранения (усиливалась профилактическая направленность, появлялись новые отрасли). Ухудшение здоровья населения репродуктивного возраста, уменьшение числа зачатий из-за боязни инфекиий, рост материнской смертности из-за нелегальных абортов приводило к снижению рождаемости, но с помощью мер пронатальной политики отложенные рождения могут быть реализованы после окончания пандемии.

DOI: $10.20537 /$ mce2021econ06

Введение. 2020 год прошел под знаком COVID-19 и стал временем, когда население мира столкнулось с явлением, о котором знали все, но только понаслышке - с пандемией. Уже второй год месяцев все хозяйственные, общественные и прочие процессы проходят с поправкой на инфекцию, создавая впечатление, что такое происходит впервые. Но текущая пандемия - не первая, и время показывает, что каждая приводила к существенным социально-экономическим изменениям.

Цель - рассмотреть основные социально-демографические изменения, которые произошли в результате пандемий.

Методы - анализ доступной статистической, исторической и социологической информации, полученной из открытых публикаций и СМИ.

\section{1.Пандемия - распространение нового заболевания в мировых масштабах.}

«Под эпидемиями, или эпидемическими болезнями понимают такие, которые от времени до времени возникают где-либо и оттуда распространяются на большие или меньшие области, поражая сразу многих индивидуумов, и, прекратившись, долгое время не появляются. ... При одновременном распространении болезни на все населенные области земного шира или при поражении ею громадного большинства людей на более ограниченной территории, говорят о пандемии» [1]. 
«...Характер распространенных инфекционных болезней на протяжении истории человеческого рода изменился: в древнем мире свирепствовали некоторые массовые заболевания, как напр., аттическая зараза (430-425 до Р. Хр.) и чума Антонина (165-168 после Р. Хр.), которые современному человечеству совершенно незнакомы; в средние века господствовали эпидемически сифилис и бубонная чума; в новейшей истории появились ранее неизвестные азиатская холера и дифтерия».

Пандемии отмечались на протяжении всей истории, но достаточно полно описаны общественные последствия чумы в середине XIV в. почти двукратное сокращение населения Европы стимулировало миграцию крестьян в городские мастерские, где из-за нехватки рабочих росла оплата труда. Столь ощутимое изменение социально-экономической ситуации потребовало применения массовых карантинных и профилактических меры, которые на макроуровне способствовали:

- $\quad$ росту уровня жизни выживших, т.к. при аграрной экономике из-за естественной убыли населения им доставались освободившиеся земли;

- $\quad$ росту производительности труда благодаря технической модернизации, актуальной при недостатке рабочей силы;

- формированию системы общественного здравоохранения.

В начале XX в. появились первые национальные системы здравоохранения в развитых странах, вакцины против чумы, холеры, оспы, «детских инфекций» и проч., но проблемы инфекций, передающихся воздушно-капельным путем, оставались нерешенными. Главной из них оставались эпидемии гриппа, фиксировавшиеся с XII в., а самые сильные демографические и социальные удары нанесли в XVIII-XIX вв.: пандемия 1889 г. привела к снижению объема производства в России из-за массового невыхода заболевших на работу, повлекшему за собой экономический спад, суммарные убытки российской экономики от которого оказались выше, чем при чуме и холере [2].

«Испанка» 1918-1920 гг. стала первой пандемией, с которой начали бороться на правительственном уровне. Причина в том, что при низкой территориальной мобильности населения и нестабильных мирохозяйственных связей негативный демографический эффект, связанный, главным образом, с повышенной смертностью, ограничивался национальным или даже региональным уровнем, а экономический зависел от внутренней ситуации в стране. Новый фактор — глобальные транспортные сообщения — привел к тому, что «испанка» распространилась на все континенты, а в некоторых 
странах заболело 20-80\% всего населения. Остановка производственных линий из-за массовой заболеваемости рабочих вызвала падение мирового ВВП на 6.6\% и масштабную рецессию 1919-1921 гг.

Демографическое влияние пандемии «испанки» было связано с повышенной смертностью среди туберкулезных больных и беременных, поэтому после ее окончания она снизилась за счет сокращения числа зараженных. В некоторых странах из-за уменьшения числа женщин детородного возраста и ухудшения популяционного здоровья упала и рождаемость, но в других странах она выросла благодаря заместительному эффекту — реализации «отложенных рождений». Россию пандемия охватила в период Гражданской войны, совпав с эпидемией паразитарных тифов, поэтому возможен лишь приближенный расчет потерь:

- демографические - несколько миллионов человек;

- экономические - невозможно выделить из общих военных и революционных потерь, однако общая хозяйственная разруха очевидна.

Восстановление хозяйства с учетом противоэпидемических требований - создаваемая Н.А. Семашко новая система общественного здравоохранения позволяла профилактировать и быстро купировать эпидемии со сравнительно небольшими затратами:

- для всестороннего охвата населения профилактическими медико-санитарными услугами сформирована новая отрасль - курортология;

- существенное расширение подготовки медицинских работников разного уровня;

- рост женской занятости в медицине;

- медицинское обслуживание сельских и труднодоступных районов. 30 января 2020 г. ВО3 объявила чрезвычайное положение для общественного здравоохранения международного значения (PHEIC) в связи с глобальной вспышкой коронавируса SARS CoV-2. До этого состояние опасности для общественного здравоохранения международного значения объявлялось пять раз:

1) 2009 - свиной грипп (H1N1),

2) 2014 - полиомиелит в Афганистане, Пакистане и Нигерии,

3) 2014 - геморрагическая лихорадка (вирус Эбола в Западной Африке),

4) 2016 - инфекция (вирус Зика),

5) 2019 - инфекция (вирус Эбола). 
Вспышка пандемии в 2020 г. - лишь вопрос времени: «B течение многих лет эксперты предупреждали о риске вспьшки пандемии и особенно о зоонозных инфекциях, т.е. тех, которые передаются животными. К сожалению, до сих пор их предупреждения игнорировались, и мы сейчас сталкиваемся с последствиями этого» [3].

Таблица 1. Экономические и демографические последствия некоторых вирусных пандемий XX в. Источник. [4]

\begin{tabular}{|l|c|c|c|}
\hline Вирус & $\begin{array}{c}\text { Число заражен- } \\
\text { ных, тыс. человек }\end{array}$ & $\begin{array}{c}\text { Летальный ис- } \\
\text { ход, тыс. человек }\end{array}$ & $\begin{array}{c}\text { Экономиче- } \\
\text { ский ущерб }\end{array}$ \\
\hline Свиной грипп & 220 & 2 & $\begin{array}{c}1 \text { трлн \$ (1.5\% } \\
\text { мирового ВВП) }\end{array}$ \\
\hline $\begin{array}{l}\text { Атипичная } \\
\text { пневмония }\end{array}$ & 8.437 & 0.813 & 59 млрд \$ \\
\hline Лихорадка Эбола & 28.54 & 11.315 & 32.5 млрд \$ \\
\hline
\end{tabular}

Поскольку к середине XX в. мировая экономика уже имела стабильные межнациональные связи, то все вирусные пандемии, начиная с азиатского 1957-1958 гг. и гонконгского гриппов 1968-1969 гг., быстро поражали население разных стран и деформировали трансхозяйственные отношения (табл. 1).

\section{2. Рождаемость и смертность в России и в мире во время панде-} мии. Пандемии всегда сопровождались изменениями в рождаемости, вызванные ухудшением здоровья населения репродуктивного возраста, снижением числа зачатий из-за боязни инфекций, а также ростом материнской смертности в результате нелегальных абортов. Обычно за год в мире умирает около 56 млн чел. (около 153000 человек в день), и коронавирус принципиально не изменил это (табл. 2).

Таблица 2. Число рождений и смертей в мире. Источник: [5-7].

\begin{tabular}{|l|c|c|c|c|c|}
\hline & 2019 & \multicolumn{2}{|c|}{2020} & \multicolumn{2}{c|}{2021} \\
\hline & ОКР/ОКС & Человек & ОКР/ОКС & $\begin{array}{c}\text { Весь год, } \\
\text { человек }\end{array}$ & $\begin{array}{c}27.01 .2021, \\
\text { человек }\end{array}$ \\
\hline Родилось & 19 & 155676622 & 19 & 11546200 & 378400 \\
\hline Умерло & 7 & 60816965 & 7 & 45333000 & 147400 \\
\hline
\end{tabular}


Репродуктивные намерения. В начале пандемии COVID-19 СМИ многих стран выдвигали версии о новом «бэби-буме» как результате вынужденной домашней самоизоляции. Интернет-опрос, проведенный в Италии на третьей неделе карантина (1482 респондентов в возрасте 1846 лет, 944 женщин и 538 мужчин, находившихся в стабильных гетеросексуальных отношениях по крайней мере в течение года) показал, что:

- на фоне локдауна каждый третий из тех, кто собирался завести детей, отложил свои планы на родительство;

- каждый пятый допустил возможность стать родителем в этот период;

- частота супружеских контактов в период самоизоляции не изменилась, однако 58\% из них связали отказ от намерений зачать ребенка с экономическими трудностями (40\% сообщили об ощутимом сокращении ежемесячного дохода) и потенциальными негативными последствиями ковида для беременности;

- $11.5 \%$ (140 человек), в основном, женщины, заявили, что возникшее в связи с пандемией дополнительное время на обдумывание вызвало желание стать родителями, но только шестеро из них попытались забеременеть в этот период.

Регулирование рождаемости. Несмотря на рекомендации ВОЗ «продолжать предоставление услуг в области сексуального и репродуктивного здоровья, таких как доступ к контрацептивам без рецепта во время кризиса COVID-19», в реальности службы охраны репродуктивного здоровья были частично либо полностью закрыты, а сократившаяся трансграничная торговля материалами для производства современных средств контрацепции привела к их дефициту. Таким образом, доминирующий в последние годы «стимулированный» рост числа рождений стал «вынужденным». Снижение доходов и отсутствие доступа к квалифицированным поставщикам медицинских услуг вынудили женщин переходить на менее эффективный способ предохранения или даже полностью отказаться от контрацептивов. Аборт остался единственным способом регулирования числа рождений, однако социальное дистанцирование и другие противоинфекционные меры осложнили доступ и к нему.

Хотя искусственное прерывание беременности в последние годы во всем мире теряет популярность и подвергается общественному осуждению, при отсутствии эффективной контрацепции это единственный вариант отказа от непланируемых рождений; поскольку проведение абортов ограничено сроками беременности и национальным законодательством, то их отсрочка из-за коронавируса может привести к увеличению 
небезопасных, в том числе криминальных абортов с осложнениями вплоть до летальных исходов. В связи с этим руководство ВОЗ рекомендовало странам обеспечить постоянный доступ к контрацепции и безопасным абортам в полном объеме на протяжении всей пандемии. Но через несколько месяцев после начала пандемии многие женщины оказались в ситуации, когда делать безопасный медицинский аборт стало поздно, и вынуждены были рожать нежеланного ребенка либо прерывать беременность с нарушением закона.

Организация Marie Stopes International (услуги по планированию семьи): в 37 странах за январь-июнь 2020 г. контрацептивную помощь получили почти на 2 млн женщин меньше, чем за тот же период прошлого года; это означает 900 тыс. незапланированных беременностей, 1,5 млн небезопасных абортов и 3.1 тыс. материнских смертей. При этом национальные политики в этом вопросе различались:

- некоторые штаты США - введен полный запрет абортов;

- Англия - предлагаются таблетки для медикаментозного аборта всем желающим;

- Франция - медикаментозный аборт доступен даже через систему телемедицины.

В Сингапуре, где рождаемость очень низкая (СКР - 1.2), правительство ввело «пандемический бонус» (единовременное пособие, стимулирующее рождения во время эпидемических ограничений). Хотя здесь многоступенчатая система родовых выплат, и впервые родившая женщина получает 10 тыс. сингапурских долл. (около \$7.3 тыс.), после информации о том, что «эпидемия коронавируса заставила некоторых честолюбивых родителей отложить свои планы по рождению детей», было принято решение существенно повысить эту сумму.

В России, по данным Росстата, за январь-октябрь 2020 г. рождаемость снизилась по сравнению с прошлым годом, и на свет появилось лишь 1193.4 тыс. новорожденных (табл. 3), но, по мнению некоторых экспертов, в условиях пандемии «население решит подстраховаться и станет рожать ради детских пособий» и гарантии от потери работы: если «осмысленно пойти в декрет - девять месяцев точно не уволят и еще три года декретных выплат». 
Таблица 3. Показатели естественного движения населения РФ.

\begin{tabular}{|c|c|c|c|c|c|c|}
\hline & \multicolumn{3}{|c|}{ Январь-октябрь } & & & Справочно \\
\hline & \multirow{2}{*}{$\begin{array}{l}\text { тысяч } \\
2020\end{array}$} & \multirow[b]{2}{*}{2019} & \multirow[b]{2}{*}{$\begin{array}{l}\text { Прирост, } \\
\text { снижение }\end{array}$} & \multicolumn{2}{|c|}{ на тыс. чел } & на 1000 \\
\hline & & & & 2020 & 2019 & \\
\hline Родившихся & 1193.4 & 1250.6 & -57.2 & 9.8 & 10.2 & 10.1 \\
\hline Умерших & 1661.4 & 1510.2 & +151.2 & 13.6 & 12.4 & 12.3 \\
\hline $\begin{array}{l}\text { Из них детей до } \\
1 \text { года }\end{array}$ & 5.4 & 6.2 & -0.8 & 4.42 & 4.82 & 4.92 \\
\hline $\begin{array}{l}\text { Естественный } \\
\text { прирост/убыль }\end{array}$ & -468.0 & -259.6 & & -3.8 & -2.2 & -2.2 \\
\hline Браков & 662.3 & 801.2 & -138.9 & 5.4 & 6.6 & 6.5 \\
\hline разводов & 457.4 & 513.5 & -56.1 & 3.7 & 4.2 & 4.2 \\
\hline
\end{tabular}

С начала карантина аборты были негласно включены в число плановых операций, проведение которых отложено до стабилизации эпидемической ситуации, что воспринято неоднозначно: представители Патриаршей комиссии РПЦ по вопросам семьи, защиты материнства и детства предложили официально включить искусственное прерывание беременности в список отложенных операций, а многие женские объединения выступили резко против. Результат - как отказы в абортах по ОМС (Нижегородская область и Челябинск - без медицинских показаний только в исключительных случаях), так и упрощение процедуры за счет отмены психологического предабортного консультирования. Башкортостан: общее число абортов за первое полугодие 2020 г. уменьшилось на 5\% по сравнению с аналогичным периодом прошлого года.

Один из компонентов современной рождаемости - вспомогательные репродуктивные технологии (ВРТ), основанные на экстракорпоральном оплодотворении (ЭКО) Поскольку ЭКО предполагает оперативное вмешательство, то программы ВРТ были отнесены к плановым операциям и оказались зависимыми от глобальных противоэпидемических мер. Рекомендации по ограничению проведения лечебных циклов ВРТ на фоне пандемии были выпущены в первые дни локдауна национальными и международными объединениями врачей-репродуктологов, и в соответствии с ними большинство процедур, связанных с ЭКО, были приостановлены, в некоторых репродуктивных клиниках работали ковидные 
госпитали, где профильные лечебные протоколы выполнялись лишь частично, используя криозаморозку до окончания пандемии. В регионах, запретивших все виды амбулаторной помощи, два месяца доступным оставалось лишь онлайн консультирование.

Хотя процедуры ЭКО - основная часть прибыли любой клиники репродуктологии, и частной, и государственной, по опросу на середину марта $45 \%$ врачей-репродуктологов поддержали необходимость отложить плановую терапию бесплодия в регионах с повышенным риском заражения коронавирусом. Только в июне Министерство здравоохранения РФ одобрило рекомендации «ВРТ и Covid», разработанные Российской ассоциацией репродукции человека (РАРЧ), в том числе и потому, что исследования доказали более низкие риски возможного негативного влияния коронавируса на процесс оплодотворения и развитие эмбриона при ЭКО, чем при зачатии естественным путем. Однако за январь-июль 2020 г. было выполнено всего 32632 цикла ЭКО за счет средств базовой программы ОМС, что составило $45.3 \%$ годового плана, что вдвое сократило ожидаемое число новорожденных, зачатых «в пробирке» (в 2018 г. таких детей было 37987 - около $2 \%$ всех российских новорожденных).

\section{3. Социально-экономические факторы демографического раз-} вития во время и после пандемии. Экономические последствия пандемий можно разделить на прямые и косвенные. Прямые - это больничные и лекарственные расходы, потерянные рабочие дни и проч., физические потери отраслей (массовое уничтожение домашней птицы из-за птичьего гриппа, затоваривание магазинов модной одежды во время обязательной самоизоляции и проч.). Косвенные означают мультипликативный эффект от прямых потерь, дополненные потерями от снижения и переструктуризации потребления, затратами на пенсии по инвалидности и проч. Чтобы сократить их, после вспышки лихорадки Эбола в ряде стран Западной Африки в 2013-2014 гг. Всемирный банк (ВБ) учредил специальный фонд Pandemic Emergency Financing Facility (PEF), который летом 2017 г. выпустил «пандемические облигации» на \$425 млн для борьбы с шестью вирусами: новыми вирусами гриппа, коронавирусами, филовирусами, вирусом геморрагической лихорадки Ласса, вирусом лихорадки долины Рифт, вирусом конго-крымской геморрагической лихорадки. Прибыль от капиталовложений предполагалась в случае, если один из этих вирусов достигнет определенных темпов распространения 
и летальности. По оценкам ВБ, число погибших от лихорадки Эбола сократилось бы на 90\%, если бы страны имели доступ к финансированию на ранних стадиях распространения вируса; на борьбу с эпидемией международные организации потратили около \$7 млрд. Пандемия COVID-19 заморозила не только системы здравоохранения, сократив доступ и к первичной, и к амбулаторной специализированной помощи (например, в Польше такие проблемы отмечали до 70\% пациентов), но и экономику в этом году ожидается снижение ВВП Евросоюза в среднем на 7.4\%.

Коронавирус COVID-19 показал также слабые стороны и риски, связанные с глобализацией. Открытость международной экономики и легкость путешествий способствовали распространению болезни - по данным международной организации авиаперевозок, в 2018 г. по миру путешествовали 4.3 млрд человек (половина населения Земли). Пандемия фактически привела к краху принципов глобализации, заставив закрыть границы, ограничить международные поездки и понять, что глобальные цепи поставок делают страны зависимыми от своих конкурентов в области жизненно важной фармацевтики и медицинского оборудования.

После модернизации системы общественного здравоохранения во многих странах в последние годы инфекционная служба значительно сократилась, поскольку планово предполагала наличие свободных коек, финансируемых из бюджета; из-за нарушения этого принципа по всему миру пришлось перепрофилировать больницы в «ковидные госпитали». Очевидно, что после пандемии увеличится потребность в лечении не только осложнения перенесенного коронавируса, но и обострений отсроченных хронических заболеваний, одновременно проводя подготовку к возможным новым эпидемиям. Пандемия COVID-19 оказала значительное негативное воздействие на здоровье людей, страдающих НИЗ, и продемонстрировала высокую степень их уязвимости. Самоизоляция, ограничение деятельности некоторых секторов экономики, ограничение использования общественного транспорта и закрытие учебных заведений влияет на психическое и физическое здоровье, т.к. изоляция увеличивает риск возникновения депрессивных и тревожных состояний, самоубийств. Однако, хотя пандемия представляет собой глобальный кризис общественного здравоохранения, затрагивающий все плоскости жизни человека, она ускорила развитие новых технологий и необходимость укрепления цифровых компетенций населения, особенно популяризировав телемедицину. 
Заключение. Появление нового коронавируса SARS-CoV-2 и связанной с ним болезни COVID-19 в настоящее время является наиболее важной, международной проблемой общественного здравоохранения. ВО3 признала смертность от коронавируса угрозой общественному здоровью в глобальном масштабе. Соприкосновение глобализующегося мира с пандемией нового коронавируса SARS-CoV-2 ставит человечество в беспрецедентное положение. Пандемия выявила недостатки системы здравоохранения, но также показала, насколько важны не только сотрудничество всех субъектов системы, но и голос пациентов в обсуждении здоровья. Экономические и социальные последствия пандемий влияют на репродуктивные установки, корректируя итоговую рождаемость, которая зависит от уровня развития страны и стадии перехода к регулируемой низкой рождаемости. В развивающихся странах рождаемость может даже вырасти благодаря сохранившимся пронатальным традициям. В развитых странах с медикализированным репродуктивным поведением, формируемым с учетом современных методов планирования семьи, рождаемость может вырасти в определенных группах населения, ориентированных на детоцентризм при любых социально-экономических условиях. При своевременных мерах демографической политики возможна реализация отложенных постковидных рождений.

\section{СПИСОК ЛИТЕРАТУРЫ}

1. Фрумер А.Л. Эпидемические и эндемические болезни / Энциклопедический словарь Брокгауза и Ефрона: в 86 т. (82 т. и 4 доп.). СПб., 1890-1907.

2. Протасов Н.А. Исторический очерк эпидемий гриппа в России // Военномедицинский журнал. 1891. Т. CLXXII, Вып. 3. С. 534-531.

3. Bąkowska E. Ekspert: Zdrowie publiczne jest obecnie ważniejsze niż kiedykolwiek wcześniej. URL: https://zdrowie.wprost.pl/koronawirus/10379161/ekspertzdrowie-publiczne-jest-obecnie-wazniejsze-niz-kiedykolwiek-wczesniej.html

4. Коронавирус - первая пандемия, которая обрушила фондовые рынки. URL: https://dev.by/news/istoriya-vliyaniya-epidemii-i-pandemii-na-fondovye-rynki

5. Счетчик населения Земли. URL: https://countrymeters.info/ru/World;

6. Основные демографические показатели по всем странам мира в 2019 гг. URL: http://www.demoscope.ru/weekly/app/world2019_1.php;

7. Основные демографические показатели по всем странам мира в 2020 гг. URL: http://www.demoscope.ru/weekly/app/world2020_1.php 


\section{SOCIO-ECONOMIC FACTS SURROUNDING THE PANDEMIC OF COVID-19}

\section{Rusanova N.E.}

All pandemies memorized in history of humankind led to crucial social and economic changes and modernization of existing public healthcare systems, increasing preventive and protective measures and creating new industries. Declining health status of the population in reproductive age, descending number of impregnation due to fear of infectious contraction, increase in maternal mortality from illegal abortion result in falling birth rates. However, with help of pronatalist program deterred births might be actualized after the pandemic ends. 